\title{
IDENTIDADES E CONFLITOS NAS OCUPAÇÕES URBANAS DA AMAZÔNIA
}

\author{
Msc. Charles Benedito Gemaque Souza \\ Doutorando em Desenvolvimento Sustentável do Tropico Úmido, NAEA/UFPA \\ Cidade Universitária José da Silveira Netto, Av. Perimetral, n 1. CEP 66075-650, Belém (PA) - Brasil \\ Tel.: (55 91) 3083.4237 - gemaquec@ufpa.br
}

\begin{abstract}
RESUMO
Este trabalho analisa as construções e descontinuidades identitárias nas ocupações urbanas em Belém do Pará, contribuindo para apreensão das contradições nas espacialidades e territorialidades inerentes à dinâmica interna do espaço urbano, através de uma releitura da cidade na Amazônia. Desta forma, a questão perpassa pela inclusão dessas áreas segregadas, e tudo que esta representa para o seu morador e suas relações, visto como um lugar onde os resíduos de temporalidades outras coexistem com o moderno, permitindo uma visualização das resistências de determinados usos e conteúdos diferenciados.
\end{abstract}

Palavras-chave: Identidades, Amazônia, ocupação urbana.

\begin{abstract}
This work analyses the constructions identities of urban occupations in Belém of the Pará, contributing to apprehension of the contradictions in the spatiality and territory inherent to dynamic it interns of the urbane space, through a rereading of the city in the Amazon region. In this way, the question passes by the inclusion of these segregated areas, and completely what this one represents for his resident and his relations, visa as a place where the residues of temporalities of church others coexist with the modern thing, allowing a visualization of the resistances of determined uses and differentiated contents.
\end{abstract}

Key words: Identity, Amazon, urban occupation.

\section{RÉSUMÉ}

Cet article examine les constructions identitaires et des discontinuités dans les occupations urbaines de Belém, contribuant pour la compréhension de l'espace et les contradictions territoriales inhérentes à la dynamique interne de l'espace urbain, à travers une relecture de la ville de l'Amazonie. Ainsi, la question passe par l'inclusion de ces zones de ségrégation, et tout ce qu'elle représente à ses habitants et de leurs relations, considéré comme un endroit où les déchets d'autres temporalités coexistent avec des aspects modernes, permettant une visibilité de la résistance de certains usages et contenus différenciées.

Mots-clé: Identité, Amazonie, occupations urbaines.

\section{INTRODUÇÃO}

A representação do espaço urbano se manifesta na apropriação do tempo e do espaço coletivo ou individual da cidade pela padronização socioeconômica do capitalismo. Neste sentido, a cotidianidade da metrópole se resume a um sistema de trocas voltado para simulações e virtualidades sempre direcionadas para a produção e o consumo. Os espaços construídos em Belém dentro desta lógica seguem a padronização, o consumismo e o individualismo desta racionalidade, são, portanto, espaços abstratos.

Tal reprodução do espaço ocasiona dois fenômenos concomitantes em Belém: a implosão da experiência imediata e a explosão das particularidades. Trindade Jr (1997) esclarece que a padronização espacial rompe com uma tendência a uma urbanização predominantemente ribeirinha em Belém, uma vez que as condições naturais e o processo histórico da região aproximavam a cidade para esta configuração. Todavia, o fortalecimento do espaço metropolitano coagiu não apenas as instalações físicas como redefiniu hábitos, bastante tradicionais e típicos de uma Belém não-moderna.

O espaço urbano caracteriza-se pela coação de um consumismo burocrático e individualista que, paradoxalmente, permite as condições objetivas para a sua contestação e sua superação. Neste 
sentido, o espaço é inicialmente produzido para o consumo, a exemplo de uma mercadoria, contudo, o homem guarda em seus hábitos e valores que, por mais que sejam constrangidos, são capazes de alterar normas e regras em favor do seu uso.

Com o processo da "metropolização" de Belém houve uma orientação irreversível na direção do dinheiro, do mercado e dos produtos. A cidade aproxima-se de um produto com determinado valor de troca; isto porque os investimentos na cidade tendem a ter objetivos estritamente produtivos, daí a designação de um espaço-mercadoria.

A descontinuidade entre a forma metropolitana e as diferenças espaciais se traduz na dialética entre o crescimento econômico e a vida social dentro da cidade. Embora haja uma unidade entre os dois aspectos, tornando-os inseparáveis, há um caráter conflitante entre a realidade regional e a realidade do mercado, o que torna cada vez mais complexa a elucidação deste processo. Nesta acepção, considera-se que o espaço contém e está contido nas relações sociais, logo o real é historicamente construído, tendo como representação mental o urbano, e a cidade como expressão material desta representação.

Trata-se de uma definição de cidade (e de urbano) como sendo uma projeção da sociedade sobre um local, não apenas sobre o aspecto da vida social de cada lugar, mas também no plano da representação abstrata (LEFEBVRE 1974). A cidade traduz um conjunto de diferenças, ou seja, é o espaço de coexistência da pluralidade e das simultaneidades de padrões, de maneiras de viver a vida urbana. Contudo, não se descarta a idéia de que a cidade também seja o lugar dos conflitos, onde a exploração subordina não apenas os grupos sociais excluídos como outros grupos sociais não dominantes.

Deste modo, esclarece-se que a cidade pressupõe contradições sociais, isto é, por trás deste processo de (re) produção do espaço urbano em Belém intervêm ativamente determinados atores sociais ligados às classes envolvidas.

Neste caso, os agentes hegemônicos edificam uma forma metropolitana em vistas de uma suposta necessidade da cidade, que no fundo responde a uma lógica da ordem distante. Concomitantemente, existem práticas sócio-espaciais clandestinas que, mesmo afastadas da lógica geral da forma metropolitana, conseguem exprimir posturas de resistências.

Desta maneira, nasce uma crise teórica e prática sobre Belém; teórica porque não há como definir a metrópole da Amazônia, e prática, porque embora espaços urbanos identificados com a cidade tradicional estejam cada vez menos visíveis, estes ainda não cederam totalmente para o moderno. Tamanha repressão esbarra justamente na complexidade e na descontinuidade entre o processo de crescimento urbano e o de constituição do modo de vida na cidade.

\section{A FORMA METROPOLITANA DE BELÉM}

A trajetória de atuação do poder público, ao longo dos anos, é, no plano do imediato, uma relevante conquista em direção a consolidação em Belém de um espaço urbano fragmentado, homogêneo e visivelmente destinado ao mercado. Os sinais desta padronização podem ser visíveis nos bairros atingidos a partir de novas organizações de consumo do espaço, causando o "estranhamento" em relação ao espaço produzido.

Desta forma, o espaço é desarticulado, o que implica no arrefecimento ou na perda das relações sociais mais orgânicas pelo cerceamento ou pelo distanciamento dos relacionamentos. Há um esvaziamento da vida pelo "empobrecimento do cotidiano, que remete ao esvaziamento do conteúdo social determinado pela diversidade de relações e das atividades produtoras que ali existiam" (CARLOS, 2001: 210). Neste contexto, ao mesmo tempo em que o espaço torna-se o espaço do consumo torna-se um não-lugar para o seu morador.

Com efeito, os espaços denominados públicos em Belém não se caracterizam pela copresença de grupos e nem pela pluralidade de sujeitos e de ações, prescrevendo comportamentos únicos e, 
sobretudo, não identificados com a região amazônica. Dessa forma, o morador de Belém é induzido a ser um mero consumidor de objetos alienígenas, inclusive do espaço, com isso, passa de usador para usuário do espaço.

Tal argumento é reforçado pelo desígnio da organização espacial de Belém através da dinâmica dos conflitos dos interesses dos atores sociais da cidade, definindo uma distinção no tempo e no espaço peculiar e controverso. Neste ponto, Trindade Jr. (1997) refere-se a uma exclusão socialmente difundida no processo de produção do espaço urbano, em razão das condições topográficas desfavoráveis.

O sítio urbano de Belém apresenta alguns fragmentos de terrenos de cotas mais altas, e consideráveis áreas de planícies de inundações, denominadas de baixadas . O autor citado revela que desde sua fundação, em 1616, houve em Belém uma nítida disposição de determinados agentes sociais de não ocupação destas áreas. A expansão da cidade, no entanto, provocou a centralização urbana de diversos igarapés e suas respectivas várzeas.

Com o tempo, a percepção de "baixada" em Belém acabou sendo associada a determinadas características sociais, políticas e econômicas de seus moradores ao invés das condições topográficas. De fato, tornaram-se áreas densamente ocupadas por grupos sociais marginalizados, oriundos do interior do Estado ou de outras áreas da cidade, com uma incipiente, ou nenhuma estrutura urbana.

Todavia, o processo de urbanização de Belém exigiu uma (re) configuração sócio-espacial. Um exemplo ocorreu na área que se situa em torno da avenida Visconde de Souza Franco, e da avenida General Magalhães, no centro de Belém. Trindade Jr. (1997) relata que esta se caracterizava como sendo área de "baixada", com a concentração de moradores de baixa remuneração. Entretanto, a partir de uma representação espacial "moderna" através de um projeto de drenagem e de urbanização, houve um processo paulatino de transformação nas práticas e nas formas espaciais, culminando com a expropriação dos antigos moradores.

O projeto já previa o remanejamento de centenas de famílias para uma área afastada do centro. Neste ponto, esta política promovia a valorização do espaço em dois pólos: o primeiro na área de intervenção efetiva; e o outro na área destinada aos remanejados, ampliando a malha urbana através da ação dos atores sociais excluídos. Percebe-se, então, que existem dentro de Belém terrenos de cotas altimétricas baixas que servem de área residencial ou comercial para grupos sociais menos desfavorecidos.

A produção social do espaço urbano de Belém, a partir disso, obedeceu à lógica da forma metropolitana, dinamizando as esferas de produção, de circulação e de consumo, beneficiando determinados grupos sociais. Com isto, as intervenções públicas acabam valorizando o solo de tal forma que expropriou a camada populacional mais pobre das antigas áreas de baixadas. Assim, os grupos sociais excluídos iniciaram um processo de ocupação de terrenos públicos e privados, via de regra, deficientes de equipamentos básicos e distantes da área central da cidade.

Diante dessa ação pública houve uma expropriação dos grupos sociais mais pobres das áreas atingidas, através de remanejamentos, de aumentos de encargos tributários e da especulação imobiliária. Estes buscaram abrigo na ocupação de outras áreas urbanas, que estavam propensas a uma nova intervenção, enfim, tornando-se um círculo vicioso. Contudo, as ocupações de Belém possuem um valor de troca reduzido, portanto, sujeito a um processo de manutenção.

Nesse contexto, as ocupações urbanas de Belém são territórios específicos, construídos por meio de um campo de forças, uma teia de relações sociais e uma complexidade interna que definem os limites e as alteridades, enfim, as diferenças entre as suas vivências com o resto da cidade. Tal fato, mostra que é errôneo trabalhar com uma percepção única em todas as ocupações urbanas da cidade. Mesmo que estas pareçam tão semelhantes, guardam em si individualidades comportamentais e culturais.

Todavia, o espaço historicamente concebido pelas políticas urbanas em Belém não trabalhava com esta percepção, e sim com a idéia de padronização do espaço e de embelezamento da cidade. 
Abelém (1989) explica que a intervenção pública nas ocupações de Belém reflete o descompasso entre as instituições envolvidas, somadas a total indiferença com o vivido. Logo, houve uma quebra nos vínculos sociais e nas práticas espaciais consolidadas nas ocupações urbanas atingidas, que repercute negativamente no cotidiano dos moradores que permanecem.

Além disso, a pretensa mudança social positiva não pode ser exercida somente pela máquina estatal; é necessário que as entidades da sociedade civil, inclusive os moradores atingidos, sejam partes integrantes (SOUZA, 2003). Em outras palavras, o espaço (re) produzido não pode se limitar ao concebido e ao percebido, o espaço vivido precisa ser valorizado.

Deste modo, os moradores das ocupações urbanas de Belém assistiram gradualmente à exclusão dos seus assentamentos humanos, o empobrecimento de suas relações de vizinhanças e a diminuição dos espaços públicos por meio da banalização do consumo. Todavia, os tempos indissociáveis e contraditórios aparecem justamente no estranhamento em relação às novas formas espaciais, consubstancialmente nos indivíduos com uma história, identificado no "antigamente" ou em práticas que não existem mais.

Ademais, a mobilização popular no interior das ocupações urbanas pode resgatar a noção de comunidade, mostrando, de fato, que as pessoas ainda mantêm relações entre si, mesmo com a competitividade e o individualismo impetrado pela metrópole. Assim, o movimento desvenda a idéia que o grupo confere ao espaço, por meio do seu entendimento do espaço urbano e da metrópole com base na apropriação do espaço, direcionando para luta consciente ou inconsciente contra a padronização do espaço em que vivem.

Diante disso, as ocupações urbanas designam um processo coletivo de mobilização e reivindicação, articulando o local com a (re) produção global da metrópole. Segundo Borges (1992), as ocupações "coletivas" definem-se como canais de expressão das lutas cotidianas dentro das particularidades de Belém, ou seja, o movimento de apropriação de áreas públicas e privadas torna-se um instrumento concreto de contestação e de exigência política.

Isto se explica pela configuração do espaço urbano de Belém, fragmentado territorialmente pela correlação de forças dos agentes sociais locais. Trindade Jr. (1998) mostra que o espaço socialmente produzido também está vinculado ao conjunto de relações sociais que diferencia um grupo a partir das múltiplas dimensões espaciais. Portanto, "os territórios configurados no interior do espaço metropolitano registram ações que o controlam, garantindo as espacialidades dos interesses de um ou vários agentes" (TRINDADE JR., 1998: 253).

Neste sentido, as ocupações (urbanas) dos territórios são produzidas por determinados agentes sociais, os quais delimitam nas diferenças em relação à metrópole, a partir das representações próprias alocadas no tempo e no espaço. Logo, as ocupações urbanas de Belém não foram produtos de uma padronização ou de uma estratégia deliberada, mas principalmente obra da criatividade (sobrevivência) dos seus moradores.

Com isso, trata-se de pensar a cidade através da relação espaço-tempo, expressão dos modos diferenciados de comportamentos e de hábitos. O processo de produção do espaço urbano, conforme Carlos (2001) baseia-se, de um lado, nas possibilidades de articulação entre formas de uso e de abstração do espaço e, de outro, pelo conflito de interesses que orientam as ações do Estado.

$\mathrm{O}$ fato é que a cotidianidade atual da metrópole é produto de uma racionalidade programada pela força das representações e dos objetos capturados pela imposição externa. Trindade Jr. (1998) afirma que a coação da forma metropolitana em Belém trouxe um estilo de viver que obedece a um padrão elaborado em contextos distantes da realidade regional. Assim, Belém assumiu o papel de representação espacial de consumo para as simulações e virtualidades bem delineadas como produto.

A Aldeia Cabana de Cultura Amazônica, por exemplo, é um arquétipo dos sambódromos já existentes em outras cidades do país, enquadrando uma festa tradicionalmente espontânea e popular como uma mercadoria vendida e programada no tempo e no espaço, coagindo o habitante da cidade até mesmo no seu momento de lazer. 
Este procedimento causa estranhamentos e desigualdades sociais, criando, muitas vezes uma não-identidade ou uma identidade forçada com a forma metropolitana. Trata-se, então, de uma luta para a manutenção da diferença e da singularidade que se torna coletiva à medida que busca um resgate das representações relacionadas às "organicidades" da vida cotidiana, especialmente daquela que se dá na tradição regional

É importante atentar para as possibilidades analíticas e políticas de uma metrópole como Belém, onde os resíduos são, tanto no espaço como no tempo, mais concretos que, por exemplo, em uma metrópole mais consolidada como São Paulo. As especificidades da trajetória de Belém e as identidades alocadas no espaço dão ao processo de urbanização uma peculiaridade impar.

Em suma, o espaço urbano de Belém define-se pela valorização imobiliária do núcleo central, inclusive áreas de baixadas, e pela expansão metropolitana, hierarquicamente distinguida pelos agentes sociais locais. De acordo com Trindade Jr. (1998) a concentração e a dispersão formam um par dialético dentro do processo de produção do espaço, que expressa o modelo de desenvolvimento urbano.

Trata-se, então, de uma forma metropolitana que reproduz as correlações de forças locais, no qual predomina os interesses do capital hegemônico e, por implicação, da ordem externa. Contudo, a emergência de outros agentes, como o Estado e os grupos sociais excluídos, ganham importância dentro da conformação do espaço urbano. Assim, as ocupações urbanas tornam-se partes constitutivas da metrópole, o que revela a condição de miséria destes grupos sociais excluídos da cidade e da região como um todo.

Deste modo, a dialética entre o espaço concebido e o espaço vivido (LEFEBVRE, 1974) se materializa no momento em que as temporalidades e as espacialidades ligadas à irredutibilidade do uso se fazem presente na apropriação do espaço. Em Belém tal dimensão pode ser vislumbrada principalmente, porém não exclusivamente, nas ocupações urbanas. O cotidiano de cada ocupação designa uma estratégia de sobrevivência na metrópole, bem como uma atividade contestadora por meio da construção individual e coletiva.

Enfim, a organização espacial de Belém é designada pela dinâmica dos conflitos de interesses dos atores sociais da cidade, definindo um espaço urbano com territórios e lugares diferenciados, embora articulados pela forma metropolitana. Neste contexto, as vivências e as experiências cotidianas revelam as contradições sociais alocadas no espaço e no tempo.

\section{AS IDENTIDADES AMAZÔNICAS E SUAS ESPACIALIDADES NA OCUPAÇÃO URBANA DO RIACHO DOCE}

A ocupação do terreno, hoje denominado de Riacho Doce, é produto do processo de representação do espaço urbano, cuja abstração se repete em níveis distintos e contraditórios. Trata-se de uma área da várzea da bacia do Tucunduba, no sudeste de Belém no bairro do Guamá, que se tornou atrativa para os grupos sociais excluídos.

A instalação de órgãos federais como campus pioneiro da Universidade Federal do Pará (UFPA), desencadeou uma reviravolta na trajetória de ocupação da várzea do Tucunduba. Segundo Ferreira (1989) o "efeito repulsivo " que caracterizava a produção do espaço nesta área desapareceu quando da implantação destes objetos, trazendo um estreitamento das formas de articulações do Tucunduba com o conjunto da cidade.

De fato, o Estado atuou no espaço por meio de desapropriações e a construção da organização básica para a viabilização do campus. Contudo, na esteira desse novo processo de produção espacial houve um avanço de ocupações espontâneas para uso residencial na várzea do Tucunduba, criando uma relação de conflito entre capital-trabalho-espaço centrado na luta pelo direito à moradia. 

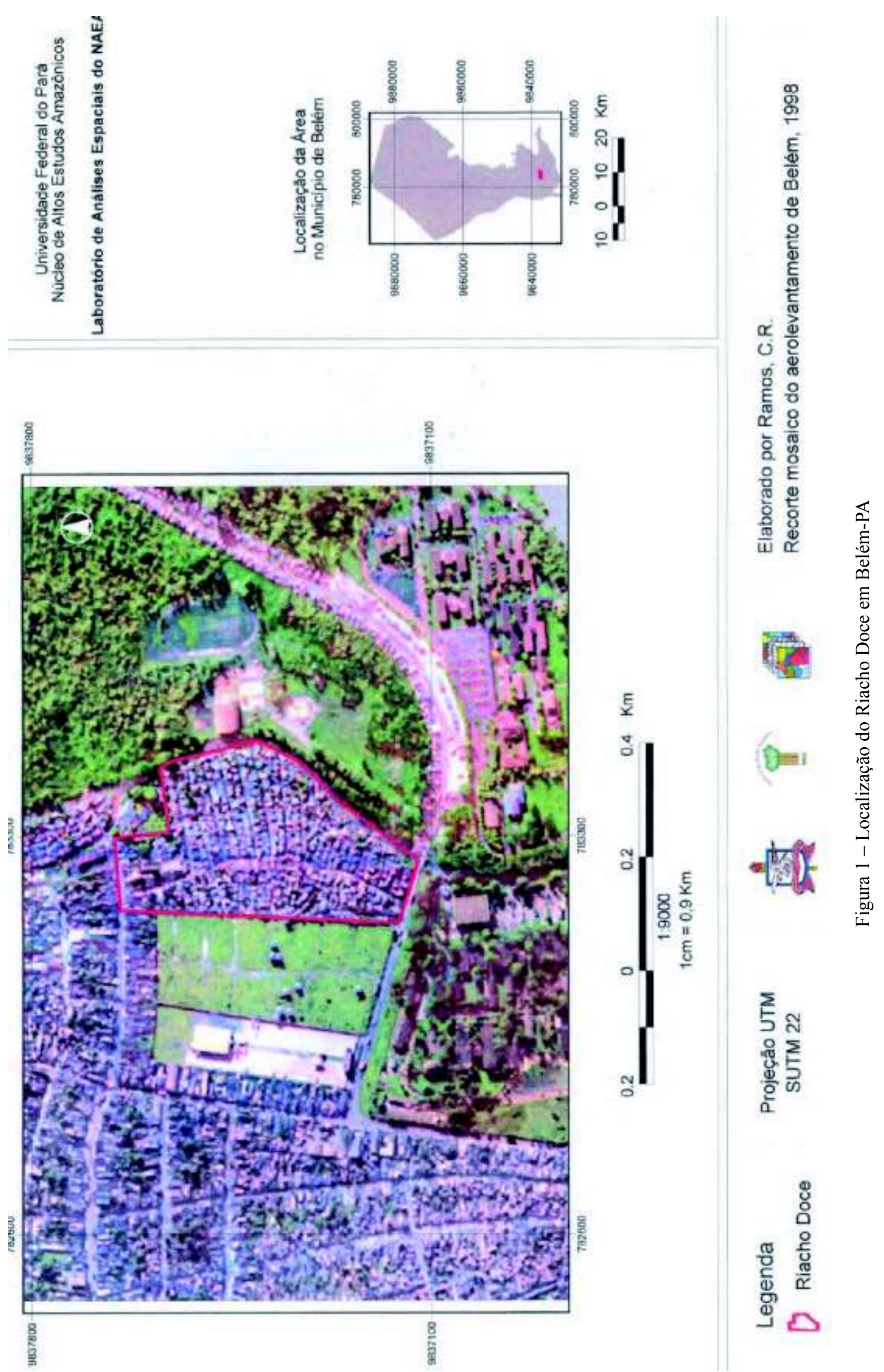
Em decorrência da falta de estrutura para fiscalizar e controlar as ocupações que aumentavam progressivamente, a área, que foi desapropriada para fins educacionais, acabou sendo destinada para a moradia. Porém, conforme Ferreira (1989) relata, havia um enorme desnível em termos de condições materiais entre o campus universitário e as áreas ocupadas contíguas.

Desta forma, percebe-se que a produção do espaço na várzea do Tucunduba permaneceu ainda caracterizada pela marginalização; uma exclusão no espaço, que não está mais relacionada com os antigos "efeitos repulsivos" ou com as condições topográficas, mas às contradições vinculados à condição de classe dos seus ocupantes. Enfim, constrói-se uma representação abstrata na cidade a partir da dialética entre a apropriação do espaço e a padronização da metrópole.

A ocupação da várzea do Tucunduba passa a ser vista como um dos territórios integrantes da forma metropolitana de Belém, uma vez que se torna produto, meio e condição do trabalho social, isto é, do espaço socialmente produzido. Deste modo, é reconhecida como uma área excluída e, ao mesmo tempo, referência no contexto de Belém, com hábitos, comportamentos e laços de parentesco e de vizinhança próprios.

Assim, a consolidação da ocupação do Riacho Doce foi marcada por diversos conflitos envolvendo os agentes sociais interessados na área, dentre os quais se destacam a Universidade Federal do Pará (UFPA), o empresário Antônio Alves e os ocupantes iniciais. Neste momento, a partir da organização dos ocupantes, constituiu-se uma mobilização comunitária em torno da territorialidade definida que possibilitou o fortalecimento de uma rede de relações políticas favorável à permanência da ocupação.

Neste aspecto, a origem do principal instrumento de ação social coletiva dos ocupantes do Riacho Doce, o centro comunitário, remonta à própria origem da ocupação urbana. Contudo, Silva (2003) argumenta que nesse primeiro momento as reivindicações limitavam-se ao direito à moradia, não incluindo outros direitos.

Diante desse quadro, evidencia-se um fenômeno comum na reprodução do espaço urbano, o desempenho desigual do Estado, enquanto agente responsável por serviços públicos, o que constitui uma parte indissociável da exclusão sócio-espacial. Deste modo, a criatividade foi amenizando as dificuldades, enquanto os serviços urbanos foram sendo implantados paliativamente.

A ocupação desta área considerada inadequada por outros agentes da produção espacial tornou-se uma alternativa de moradia e de sobrevivência. No caso da ocupação do Riacho Doce, o grande fluxo de grupos sociais excluídos oriundos do interior do Pará e de outras localidades da Amazônia, bem como aquelas expropriadas de áreas valorizadas pelas intervenções urbanas, acabou refletindo-se na forma de apropriação do espaço, criando um espaço diferenciado em Belém.

O sistema viário segue a lógica de uma espinha de peixe, cuja referência principal é a Rua da Olaria, onde se concentram os pequenos comércios da ocupação. A configuração espacial do Riacho Doce demonstra que houve uma preocupação, por parte dos moradores, com os acessos de mercadorias e de pessoas. Para Costa (2002), isto reafirma que a forma de organização identifica uma das representações utilizadas pelos atores sociais na apropriação do espaço.

O igarapé do Tucunduba tornou-se outra via de circulação essencial para os moradores, principalmente aqueles alocados nas proximidades de sua margem direita. Através deste acesso fluvial, os moradores trafegavam e comercializavam produtos com várias localidades próximas. Atualmente é o único igarapé no interior da cidade de Belém que manteve essas características; isto se deve à localização da foz no interior da UFPA, o que impediu legalmente a implementação de projetos de terraplanagem do canal, tão comum na trajetória das políticas públicas da cidade.

$\mathrm{Na}$ ocupação do Riacho Doce as atividades de sobrevivência vinculadas ao igarapé do Tucunduba são a pesqueira, a comercialização de mercadorias e o transporte de passageiros. Não obstante a degradação do igarapé e o processo de urbanização, estas atividades acabam tendo um peso importante na estratégia de obtenção de uma renda familiar suplementar.

O comércio de produtos segue uma lógica bastante peculiar. É comuns que os produtos vindos das localidades próximas sejam enviados por parentes ou vizinhos que ainda permanecem em seu 
local de origem, ou então que um ou mais membros da família deslocam-se para estas localidades, durante um determinado período (SOUZA, 2003). Entre as mercadorias encontramos madeiras, frutas regionais, tijolos, telhas, palha, açaí.

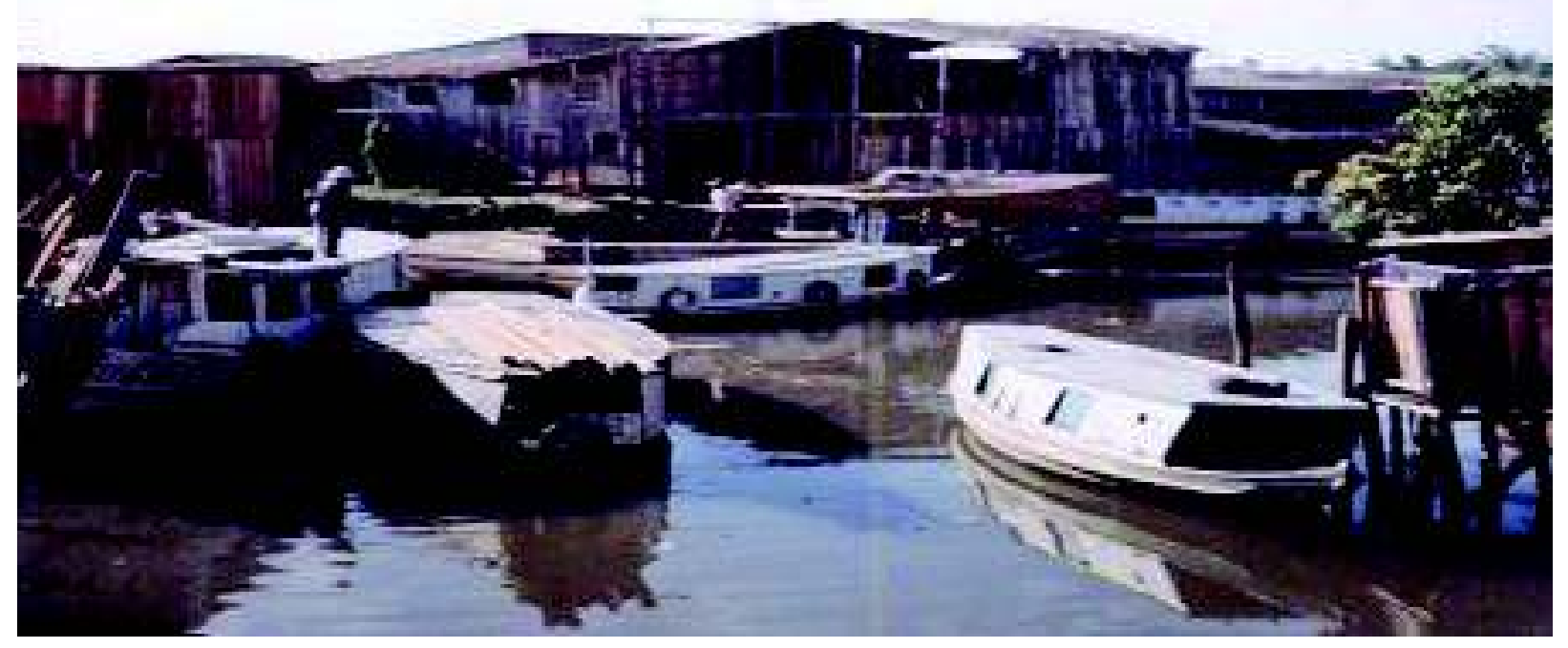

Figura 2 - Orla do Riacho Doce

Destacando as pequenas embarcações e as diversas construções às margens do igarapé do Tucunduba Fonte: Maria Goretti Tavares-2000

A atividade pesqueira, embora não seja tão difundida como nas localidades ribeirinhas, contribui regularmente para a alimentação de determinadas famílias da área. Neste caso, o morador necessita de uma pequena embarcação que permita o seu deslocamento ao rio Guamá, que margeia a capital paraense. Os peixes obtidos são normalmente para o próprio consumo.

A circulação fluvial como meio de transporte, também é bastante utilizada tanto no Riacho Doce, como em todo o Bairro do Guamá e da Terra Firme. Isto se deve as características de certas localidades amazônicas, onde o acesso só é possível pela via fluvial, além do mais, o transporte fluvial é menos oneroso. Há embarcações, pertencentes aos moradores do Riacho Doce, típicas para este tipo de deslocamento, sendo outra forma suplementar de renda para estes.

Em 2000, o censo do IBGE concluiu que na ocupação urbana do Riacho Doce havia 5607 moradores distribuídos em 1281 moradias. Um ano depois, a Secretaria Municipal de Saúde criou um banco de dados com informações sobre os moradores do Riacho Doce, por meio do programa Família Saudável. O resultado apontou a existência de 1179 famílias na área com uma média de 5,24 pessoas por domicílio (BELÉM, 2001). Ainda de acordo com esses dados, $40 \%$ das famílias do Riacho Doce são originárias de outros municípios, contudo extrapolando a informação para aquelas que nasceram em outras localidades, mas que estão residindo há algum tempo em outras áreas de Belém, estes números sobem para $54 \%$.

Neste aspecto, o cotidiano da ocupação é reflexo, também, do que foi aprendido e transmitido em sua vida anterior. Por conta disso, a experiência adquirida é caracterizada por um conjunto de componentes (materiais, sociais, intelectuais e simbólicos) que formam sistemas de relações mais ou menos coerentes entres si. Ela é vivida individualmente e coletivamente no espaço, sendo transmitida e inventada, por meio da criatividade e do uso, atitudes e idéias.

Desta maneira, as famílias oriundas de outras localidades não possuem uma identidade urbana acabada, embora estejam inseridos no ritmo da forma metropolitana. A ocupação do Riacho Doce torna-se então não somente um espaço de sobrevivência na cidade, como dissemina hábitos e comportamentos que não segue a mesma lógica da temporalidade padronizada. 
Os migrantes presentes na ocupação conseguem, através da presença de grupos de amigos e de familiares, e do igarapé do Tucunduba, uma espécie de combinação que preserva ou recria tais relações, inclusive com o espaço. O homem consegue graças a sua "arte de fazer", adaptar-se aos parâmetros espaciais elaborados pela razão moderna, que visa ao controle da sociedade (CERTEAU, 1996).

Com isto, as vivências próprias do Riacho Doce são criadas por meio de um cotidiano menos individualista e menos competitivo. Produto das relações sociais, sobretudo, as de parentesco e de vizinhança, cria-se estratégias de sobrevivência no espaço urbano (SOUZA, 2003). Desta forma, no cotidiano da ocupação existem elementos que são resquícios de seu modo de vida anterior, bem como, de sua adaptação ao urbano.

O fato é que o Riacho Doce consegue produzir um espaço diferenciado, construindo a sua própria identidade, criando representações que têm história e significado também comum às localidades de origem. Neste aspecto, a presença do igarapé contribui sobremaneira para a reprodução de um tempo amazônico menos moderno, seja pela influência da maré, pelos movimentos dos barcos ou pelas lembranças de uma vida ribeirinha e rural.

Nesse sentido, a Amazônia é reconhecida por suas diversas singularidades no tempo e no espaço, o que dificulta o esboço de uma particularidade regional. No entanto, o homem amazônico é muito ligado à natureza em que vive, designadamente como os rios e igarapés, isto porque esta é sua fonte de alimentos, de lazer, de trabalho e de deslocamento.

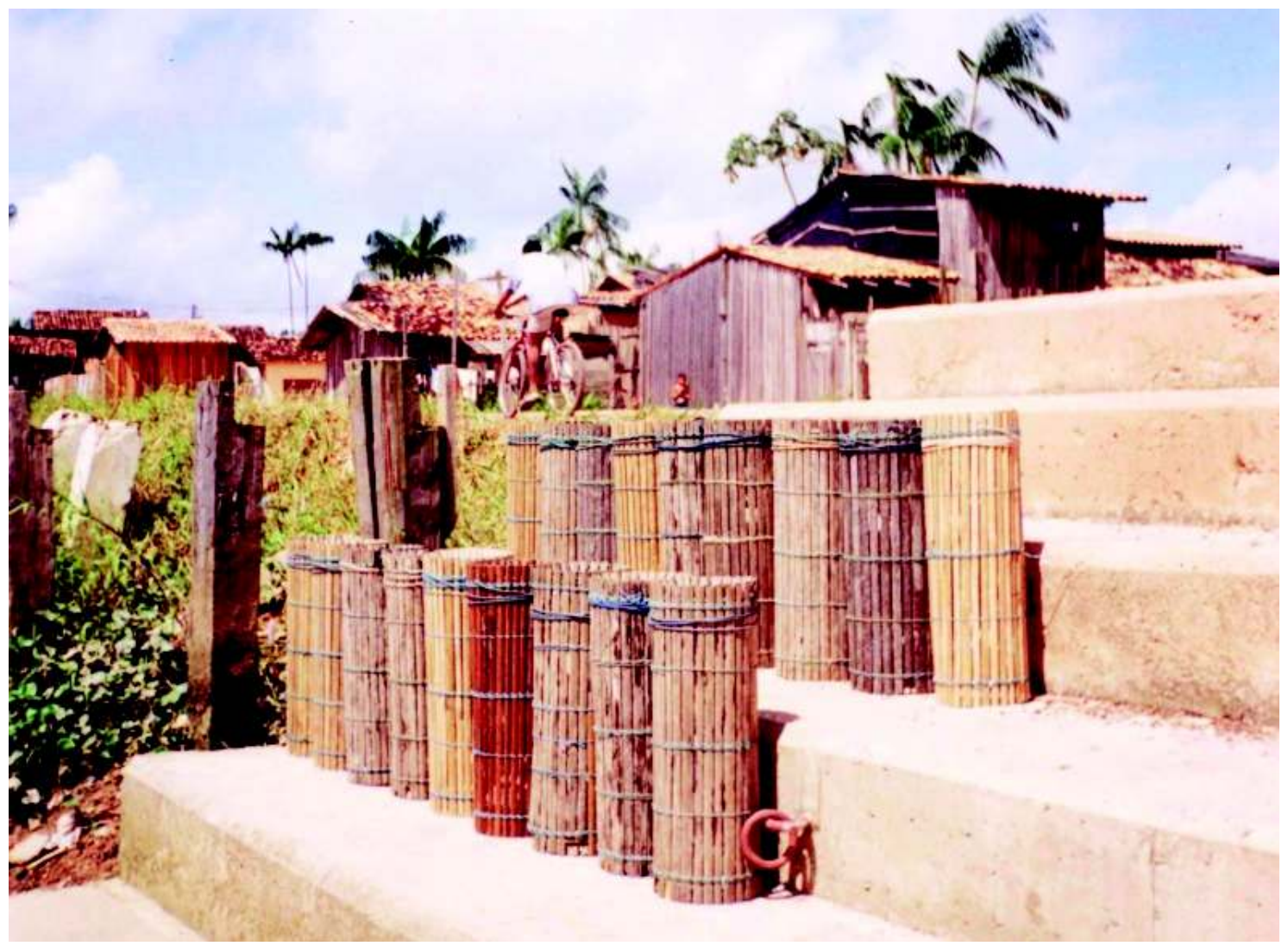

Figura 3 - Conjunto de matapís Alocados na escadaria de um pequeno porto que seria construído pela PMB, revela um exemplo de convivência de temporalidades.

Fonte: Charles B. Gemaque Souza -2002

A tipologia das moradias, por sua vez, reproduz as casas do interior do Estado, dentre outros motivos, pela facilidade de autoconstrução e pelo solo de várzea. Contudo, existe uma identidade afetiva, psicológica entre o morador e sua casa que transpõe elementos e formas que existiam ante- 
riormente, mantendo uma representação da sua experiência de vida (COSTA, 2002). Além disso, a casa representa uma propriedade a ser mantida, uma estratégia de sobrevivência na cidade e, como tal, é uma referência de estabilidade e de liberdade individual e familiar.

Há, nestes termos, uma disseminação no Riacho Doce não somente das características materiais das casas, mas do próprio conjunto de relações sociais estabelecidas em torno da casa. Dados recolhidos na própria área (SOUZA, 2003), indicam que ao longo do processo de ocupação desta, é comum encontrar ocupantes membros da mesma família, vizinhos e/ou conhecidos. Apesar disto não permitir afirmar que haja um caráter familiar na ocupação, existem laços de afetividade, de confiança e de solidariedade.

Também contribui, embora indiretamente, as dificuldades encontradas pelos ocupantes para se inserirem no mercado de emprego formal de Belém. A solidariedade parece ser, portanto, um mecanismo de sobrevivência acionado para superar as adversidades cotidianas.

Por outro lado, os moradores economicamente ativos estão engajados predominantemente em vendas e atividades informais ou temporárias de trabalho, os chamados "bicos" (BELÉM, 2001), no qual é aproveitado, de certa forma, o saber e os costumes interioranos, sendo uma das principais estratégias de sobrevivência.

De acordo com Menezes et al. (2000), entre estas alternativas existentes no Riacho Doce, as culturas de "quintais" representam bem esta identidade. Trata-se de plantações de hortaliças, fruteiras e medicinais nos quintais dos terrenos. $\mathrm{O}$ fato é que a partir de uma experiência adquirida, institui-se uma forma de agricultura familiar urbana para o consumo próprio.

Em tese, o ocupante, à medida que vai edificando sua moradia constrói uma série de vivências próprias. Costa (2002) explica que o morador articula o seu mundo privado, manifestado nas relações pessoais, com o seu mundo coletivo (público), expressado no processo de produção do seu espaço. Logo, é na dialética entre concebido e o vivido, entre as virtualidades e o uso que se define uma temporalidade diferenciada no Riacho Doce.

Giddens (1989) reforça essa idéia, quando indica que as estruturas podem não serem criadas pela ação direta do homem, mas são constantemente (re) produzidas pelas práticas cotidianas. A partir desse raciocínio, é possível afirmar que a constituição de uma forma espacial menos abstrata, como o do Riacho Doce, pode se configurar em outro processo de produção social da cidade. Se as condições de existência são cada vez mais invadidas pela estrutura abstrata (mercadológica), empobrecendo o cotidiano à medida que transforma as relações sociais em relações burocráticas. De outro lado, há resquícios de clandestinidade da ação social, no qual submerge valores desatrelados, cuja persistência é produto das singularidades contextuais.

Tal é o caso da ocupação urbana do Riacho Doce, que apesar do invólucro da forma metropolitana, traz em seu cotidiano a permanência de "rugosidades" de uma experiência adquirida em localidades não capitalistas. Deste modo, o espaço foi alicerçado também por meio de uma temporalidade diversificada, porém, lenta em relação ao ritmo das virtualidades da modernidade.

Há nestes termos, uma disseminação no Riacho Doce não somente de experiências típicas de uma particularidade regional, mas, sobretudo, de uma conformação de uma singularidade local através do modo que os ocupantes convivem hodiernamente. Neste sentido, as diversas expressões de resistências, cristalizadas no cotidiano da ocupação, resumem a pluralidade de sujeitos e ações que definem as realidades amazônicas.

\section{CONSIDERAÇÕES FINAIS}

O espaço social tem como suporte à dialética da representação (abstrata) do espaço e do espaço da representação (diferencial). Lefebvre (1974) apresenta o espaço como obra e produto do homem, ou seja, ao mesmo tempo em que o espaço é socialmente produzido, este é o objeto e a força de produção da sociedade moderna. Deste modo, o espaço social pode concretizar as abstra- 
ções inseridas nas relações sociais, do mesmo modo que efetiva a mobilização das diferenças e a insurreição do uso.

A análise da dialética do espaço significa ponderar sobre as contradições presentes no espaçomercadoria, uma abstração que se concebe enquanto mundial a partir do valor de troca. Conquanto, o homem é um ser que usa o espaço para viver de acordo com as condições naturais e históricas particulares; neste caso, o valor de troca não repercute da mesma maneira em espaços distintos (DAMIANI, 2001). Logo, a insurreição do uso envolve temporalidades e espacialidades que representem uma resistência à maneira de viver coagida pela padronização metropolitana.

Neste sentido, o espaço traduz as relações conflitantes entre o capital e o trabalho, definido dentro de uma nova economia política da cidade, que, em última instância, explica a sobrevivência do capitalismo atual. Diante de uma realidade tão complexa, é preciso resgatar uma análise espacial que envolva as suas múltiplas dimensões e sua importância para o entendimento da realidade cotidiana.

Desse modo, as singularidades da ocupação do Riacho Doce não se definem apenas por ser uma representação simbólica construída a partir das relações sociais em torno do espaço-casa, mas é um espaço vivido, socialmente entrelaçado às práticas cotidianas não modernas. Trata-se, então, de um lugar diferenciado que incorpora a cotidianidade da forma metropolitana pelos usos e conteúdos presentes na reprodução da vida social local.

Porém, o ritmo da metrópole impõe um leque necessidades supérfluas que tornam o morador um mero consumidor de mercadorias. As mudanças produtivas e tecnológicas das últimas décadas criaram obrigações pessoais e profissionais que impuseram uma dinâmica de vida acelerada e desumana.

Diante disso, a modernidade é impessoal, individualista e competitiva, criando um homem solitário que tem objetivos mais elevados do que a do simples flâneur. De acordo com Acevedo e Chaves (1996) em Belém existe uma repressão subjetiva aos espaços e às relações que não se encaixem na imagem do moderno, criando um paradoxo entre a forma metropolitana e a cultura regional.

É preciso que as diversas manifestações espaciais ligadas à identidade amazônica, manifestadas nas experiências e nas vivências das ocupações urbanas de Belém, sejam valorizadas. Criando, assim, um contraponto à coerção subjetiva e material da forma metropolitana da modernidade.

Logo, a ocupação urbana torna-se uma primeira forma de oposição ao espaço abstrato, isto é, torna-se uma estratégia de residência (resistência) do excluídos. Neste ponto, a apropriação do espaço no Riacho Doce, incorpora a dimensão do vivido, que se relaciona às relações pessoais, às experiências anteriores, às vivências próprias e às diversas atividades feitas no igarapé do Tucunduba; apesar de não descartar a inserção desses mesmos moradores na dinâmica da vida metropolitana.

A partir dessa perspectiva, é o caso de pensar em uma política de desenvolvimento que (re) aproxime definitivamente as vivências e as experiências com as ações implementadas nas ocupações urbanas, e que o morador envolvido, por sua vez, tenha a liberdade e a autonomia de desempenhar o seu papel de "co-gestor", possibilitando uma nova forma de organização espacial no contexto metropolitano de Belém, beneficiando a sociedade como um todo.

Enfim, pode não representar uma transformação imediata no sistema como um todo, entretanto, através dos elementos destes universos singulares, articulados à totalidade, é que podemos apreender os tempos e os espaços, refazendo, a cada momento, os caminhos aparentemente já definidos pela história.

\section{REFERÊNCIA BIBLIOGRÁFICA}

ABELÉM, Auriléia Gomes. Urbanização e remoção: por que e para quem? Belém: Centro de Filosofia e Ciências Humanas / NAEA / UFPA, 1988.

ACEVEDO, Rosa; CHAVES, Ernani. Imagens de Belém, paradoxo da modernidade e cultura amazônica. Papers do NAEA n 56, 1996. 
BELÉM, Prefeitura Municipal de. Plano de desenvolvimento local Riacho Doce e Pantanal. Volume 1: Concepção geral. Secretaria Municipal de Coordenação Geral do Planejamento e Gestão.Belém, 2001.

BORGES, Maria Vitória Paracampo. Cidadania e Direito de morar: a prática de ocupações coletivas e movimento de posseiros de "Jaderlãndia"- Ananindeua-Pará. 1992. 104p. Dissertação (Mestrado em Planejamento do Desenvolvimento) Núcleo de Altos Estudos Amazônicos/UFPA, Belém, 1992.

CARLOS, Ana Fani Alessandri. Espaço-Tempo da metrópole São Paulo: contexto, 2001.

CERTEAU, Michel de. A invenção do cotidiano: vol. 1, Artes de fazer. Petrópolis: Vozes, 1994.

COSTA, Solange M. Gayoso da. Razões ou ilusões de estabilidade: representações e referências imaginárias sobre a habitação na "ocupação espontânea" Riacho Doce-Belém-Pará. 2002. 85p. Dissertação (Mestrado de Sociologia) Centro de Filosofia e Ciências Humanas/UFPA, Belém, 2002.

DAMIANI, Amélia Luisa. As contradições do espaço: da lógica (formal) à (lógica) dialética, a próposito do espaço. In:DAMIANI, Amélia Luisa et al. O espaço no fim do século. A nova raridade. São Paulo: Contexto, 2001.

FERREIRA, Carmena F. Produção do Espaço Urbano e Degradação Ambiental: Um Estudo sobre a várzea do Tucunduba. Belém - Pará. 1995. 120p. Dissertação (Mestrado em Geografia). Departamento de Geografia - FFCH/ USP, São Paulo, 1995.

GIDDENS, Anthony. A constituição da sociedade. São Paulo: Martins Fontes, 1989.

LEFEBVRE, Henri. La production de l'espace. Paris: Ed anthropes, 1974.

MENEZES, Antonio J. Elias Amorim et al. Agricultor familiar: impactos da mudança para a cidade. Trabalho de mestrado do Núcleo de Estudos Intergrados sobre Agricultura Familiar NEIAF/UFPA. 2000.

SILVA, Ana Maria. A participação social no Plano de Desenvolvimento Local do Riacho Doce e Pantanal. 2003. 75p. Monografia (Especialização em Serviço Social) Centro de Serviço Social \UFPA, Belém, 2003.

SOUZA, Charles B Gemaque. Desenvolvimento local e (re) apropriação da cidade: reflexões sobre o PDL Riacho Doce. 2003. 69p. Monografia (Especialização em Desenvolvimento da Amazônia) Núcleo de Altos Estudos Amazônicos, Belém, 2003.

TRINDADE JR, Saint Clair Cordeiro da. Produção do espaço e uso do solo urbano em Belém. NAEA/ UFPA, Belém, 1997.

TRINDADE JR, Saint Clair da. A cidade dispersa: Os novos espaços de assentamentos em Belém e a reestruturação metropolitana. 1998. 205p. Tese (Doutorado de Geografia Humana). Departamento de Geografia FFLCH/ USP. São Paulo. 1998.

Trabalho enviado em janeiro de 2010 Trabalho aceito em abril de 2010 